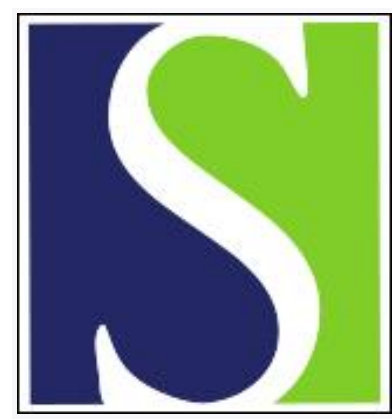

Scand J Work Environ Health 2004;30(5):350-355

https://doi.org/10.5271/sjweh.822

Issue date: Oct 2004

\title{
Cancer incidence of Nordic asphalt workers
}

by Randem BG, Burstyn I, Langård S, Svane O, Järvholm B, Kauppinen T, Bergdahl IA, Johansen C, Hansen J, Partanen T, Kromhout H, Ferro G, Boffetta P

Affiliation: Rikshospitalet University Hospital, Oslo, Norway.

Refers to the following text of the Journal: 1999;25 suppl 2:1-116

The following articles refer to this text: 2004;30(5):337-338;

2007;33(6):454-464

Key terms: asphalt worker; bitumen; bladder cancer; cancer incidence; epidemiology; lung cancer; nordic; road paving

This article in PubMed: www.ncbi.nlm.nih.gov/pubmed/15529798 


\title{
Cancer incidence of Nordic asphalt workers
}

\author{
by Britt Grethe Randem, MD, I Igor Burstyn, PhD, ${ }^{2,3}$ Sverre Langård, MD, ${ }^{1}$ Ole Svane, PhD, ${ }^{4}$ Bengt \\ Järvholm, MD, ${ }^{5}$ Timo Kauppinen, PhD, 6 Ingvar A Bergdahl, PhD, ${ }^{5}$ Christoffer Johansen, MD, Johnni \\ Hansen, PhD, ${ }^{7}$ Timo Partanen, PhD, ${ }^{6}$ Hans Kromhout, PhD, ${ }^{2}$ Gilles Ferro, ${ }^{8}$ Paolo Boffetta, MD ${ }^{8,9}$
}

Randem BG, Burstyn I, Langård S, Svane O, Järvholm B, Kauppinen T, Bergdahl IA, Johansen C, Hansen J, Partanen T, Kromhout H, Ferro G, Boffetta P. Cancer incidence of Nordic asphalt workers. Scand J Work Environ Health 2004;30(5):350-355.

\begin{abstract}
Objectives The aim of the study was to investigate cancer risk following employment in the asphalt industry. Methods Cancer incidence was studied among 22362 male asphalt workers employed for more than one season in jobs entailing exposure to bitumen (mainly road pavers) in Denmark, Finland, Norway, and Sweden. These workers are part of a European cohort of asphalt workers, for which results on mortality have been reported. The follow-up was almost complete, and reference rates were obtained from national cancer registries.

Results The incidence of cancer was reduced in all four countries [overall standardized incidence ratio (SIR) $0.89,95 \%$ confidence interval (95\% CI) $0.86-0.94]$. Lung cancer incidence was increased in all four countries, yielding an overall SIR of 1.21 (95\% CI 1.07-1.36), but no trend was detected according to time since first employment. No overall increased incidence of bladder cancer was observed, but there was a suggestion of a tendency towards higher risk with longer time since first employment, with a relative risk of 1.85 (95\% CI 0.903.78 ) for more than 30 years versus $1-14$ years (P-value for trend 0.1 ). The incidence of lip and stomach cancer was nonsignificantly increased, and the excess was present mainly in Denmark. No increased incidence was detected for other neoplasms, notably malignant melanoma, nonmelanoma skin cancer, and kidney cancer.

Conclusions The results of this study confirm the pattern of cancer risk detected in the mortality analysis of the European cohort; in addition, they provide suggestive evidence of an excess risk of bladder cancer among asphalt workers.
\end{abstract}

Key terms asphalt workers, bitumen, bladder cancer, epidemiology, lung cancer, road paving.

Asphalt is a mixture of crushed stone and bitumen that is widely used as paving material. In the Nordic countries, about 10000 workers are currently employed in asphalt work, including road paving, asphalt mixing, and special applications.

Bitumen, which is used as a binder in road paving, consists of hundreds of different chemical substances. Among these is a high proportion of paraffinic and naphthalenic hydrocarbons. Small quantities of mixed polycyclic aromatic hydrocarbons $(\mathrm{PAH})$, on the order of nanograms per cubic meter, are found in bitumen fume and vapor $(1,2)$. It used to be common practice to mix the bitumen with coal tar to improve the binding properties. Coal-tar fume has a 100-1000 times higher PAH content than bitumen fume (1). Coal tar is a known human carcinogen $(3,4)$. Therefore, exposure to coal tar is the most prominent potential confounder in studies of bitumen fume carcinogenicity among asphalt

1 Rikshospitalet University Hospital, Oslo, Norway.

2 Division of Occupational and Environmental Health, Institute for Risk Assessment Sciences, Utrecht University, Utrecht, The Netherlands.

3 Department of Public Health Sciences, Faculty of Medicine and Dentistry, University of Alberta, Edmonton, Canada.

4 Danish Working Environment Service, Copenhagen, Denmark.

5 Occupational Medicine, Department of Public Health and Clinical Medicine, Umeå University Hospital, Umeå, Sweden.

$6 \quad$ Finnish Institute of Occupational Health, Helsinki, Finland.

7 Danish Cancer Society, Copenhagen, Denmark.

8 International Agency for Research on Cancer, Lyon, France.

9 German Cancer Research Center, Heidelberg, Germany.

Correspondence to: Dr Paolo Boffetta, International Agency for Research on Cancer, 150 cours Albert-Thomas, F-69008 Lyon, France. [E-mail: boffetta@iarc.fr] 
workers (5). Asphalt companies in the Nordic countries stopped adding coal tar to bitumen in the mid-1960s or early 1970s.

The Nordic countries have special work conditions in the asphalt industry. The weather is colder than in most of the rest of Europe, and the work seasons are shorter, especially in the northern and inland parts of the countries. Different types of asphalt-paving materials are produced according to the characteristics of the road surface, and certain asphalt paving types are preferred for very cold climates. Mastic asphalt, which has a higher-than-average bitumen content, is often used for paving indoors, in garages, and for industrial floors. Paving indoors and inside tunnels may lead to higher exposures to bitumen fume and $\mathrm{PAH}(6,7)$.

The problem of cancer risk due to employment in the asphalt industry, and of the carcinogenicity of bitumen fume in particular, has recently been addressed in a large mortality study of European asphalt workers, in which a small increase in the risk of lung cancer mortality was detected among asphalt workers in a comparison with the general population (8). The study also provided some evidence of an exposure-response relation between bitumen-fume exposure and the risk of lung cancer mortality, although confounding could not be excluded as an explanation for these observations (9, 10). Mortality studies are, however, not suitable for investigating neoplasms with reduced lethality. For these neoplasms, incidence studies should be carried out. We investigated the incidence of cancer in relation to employment in the asphalt industry in the Nordic component of the European study, since, in these countries, exposure circumstances are comparable and nationwide cancer registration is available.

\section{Study population and methods}

The study population was comprised of asphalt workers exposed to bitumen in Denmark, Finland, Norway, and Sweden. The numbers are shown in table 1. This study population is part of the larger cohort of asphalt and other workers assembled for an epidemiologic study of cancer mortality among European asphalt workers coordinated by the International Agency for Research on Cancer (IARC) $(8,11)$. The individual results from the following three of the four countries have been reported elsewhere: Finland (12), Norway (13, 14), and Sweden (15). The participants included in the present incidence analysis comprised only "bitumen workers" (group 1), as defined in the European cohort.

Name, address, birth date and social security number, company number and work history in the form of job titles, and start and end dates of employment in specific jobs were obtained from the payroll and personnel records of asphalt companies in all four countries but Sweden. The companies carried out asphalt mixing and paving, and, in Denmark and Finland, they represented a subset of the asphalt companies in these two countries. In Norway, all major asphalt companies were included in the study. In Sweden, the asphalt workers were identified from the records of a nationwide occupational health service, the Swedish Construction Industry's Organization for Working Environment Safety and Health, which existed between 1969 and 1992 and covered about 300000 workers (16).

The workers' job histories during employment in the companies included in the study were coded according to an ad-hoc classification scheme. Details on exposure circumstances, including length of paving season, were obtained from the participating companies via a standard questionnaire administered by mail to knowledgeable persons in each company (Denmark, Finland, and Norway) or to representatives of the national asphalt industry (Sweden). The cohort members were classified as (i) road pavers, (ii) asphalt-mixing plant workers, (iii) roofers (mainly from Denmark and Finland), (iv) mixed workers and workers unknown as either pavers or mixers (only from Norway and Sweden), and (v) other bitumen workers (only from Denmark, Finland and Norway). The group of "other bitumen workers" consisted mainly of workers from Denmark, most of whom were likely to be road pavers. The length of the season varied from 4 to 12 months between the companies and geographic regions, and the definition of a season for a worker varied accordingly. Dates of start and end of specific jobs were not complete for the Swedish workers. In that country, the duration of work was assumed to be one season of employment for workers with one health examination and the difference in time between the first and the last health examination for workers with several examinations.

The start of follow-up varied among the Nordic countries from 1953 to 1971, and the end of follow-up varied between 1994 and 1999 (table 1). Women were excluded because of their small number. Only workers with more than one season of employment in the industry were included in the analyses, which resulted in 22

Table 1. Number of asphalt workers and person-years under observation by country.

\begin{tabular}{lcccr}
\hline Country & $\begin{array}{c}\text { Period } \\
\text { of } \\
\text { employment }\end{array}$ & $\begin{array}{c}\text { Period } \\
\text { of } \\
\text { follow-up }\end{array}$ & $\begin{array}{c}\text { Workers } \\
\text { (N) }\end{array}$ & $\begin{array}{c}\text { Person- } \\
\text { years } \\
\text { (N) }\end{array}$ \\
\hline Denmark & $1953-1996$ & $1968-1996$ & 9652 & 158313 \\
Finland & $1925-1996$ & $1969-1994$ & 2642 & 44589 \\
Norway & $1914-1999$ & $1953-1999$ & 5687 & 110945 \\
Sweden & $1925-1992$ & $1971-1995$ & 4381 & 65147 \\
\hline Total &. &. & 22362 & 378994 \\
\hline
\end{tabular}


362 Nordic workers. This study population yielded 378 994 person-years of observation. This figure differs slightly from that reported in previous publications (11) because of minor differences in the data handling.

The Nordic countries all have national cancer registries, where all new cases of cancer are recorded. Their registers are regarded as nearly complete (17). The registration of cancer cases started in 1940-1953. For the identification of cancer cases among the workers, the study cohort register in each country was linked to the national cancer registry via the personal identification numbers. Given the requirement of more than one full season of employment for inclusion in the cohort, workers were observed for cancer incidence from the start date of the second year of follow-up until emigration, death, or the end of the follow-up. A total of 129 workers emigrated, and 3 were lost to the follow-up.

Our analysis was based on a comparison between the observed and expected numbers of incident cancer cases. The expected number of cases in each country was derived by multiplying the accumulated person-years across age and calendar-year strata by the national incidence rates of the entire population. Five-year periods and age-specific rates were used. Standardized incidence ratios (SIR) were calculated as the ratio between the observed and expected values. The $95 \%$ confidence intervals $(95 \% \mathrm{CI})$ of the standardized incidence ratios were estimated with the assumption of a Poisson distribution of the cancer cases. The SAS statistical package (SAS Institute, Cary, NC, USA) was used. The relation between the relative risk of cancer and the time since first employment was examined in a Poisson regression using a priori defined categories of time since first employment and adjustment for potential confounding by age, calendar period, and country. In this analysis, trend was tested by fitting a continuous variable across the categories of exposure. STATA 8.0 (Stata Corporation, College Station, TX, USA) was used to estimate the Poisson regression models.
Limited information on smoking status was available in Norway, where data on smoking were collected from occupational health services connected to the companies. Information on ever-smoker status was obtained from 799 men, mostly from the 1980s, and it was compared with the results of national surveys.

\section{Results}

During the follow-up period, 1447 asphalt workers developed cancer, resulting in a standardized incidence ratio of 0.89 (95\% CI 0.86-0.94) (table 2). A deficit was present for the overall cancer incidence in all four countries. The lung cancer incidence was elevated, based on 290 observed cases and a standardized incidence ratio of 1.21 (95\% CI 1.07-1.36), and the increase in incidence was detected in all four countries. There were four cases of pleural cancer, two from Sweden and one each from Denmark and Finland, yielding a standardized incidence ratio of 4.23 (95\% CI 1.15-10.83), although comparisons with national figures should be interpreted with caution because of possible differences in the definition of pleural cancer in the cohort follow-up versus the reference rates. The incidence of lip and stomach cancer incidence was nonsignificantly increased (SIR 1.46, 95\% CI 0.89-2.26, and 1.26, 95\% CI 0.991.57 , respectively). For both cancers, most of the excess cases came from the Danish cohort. Asphalt workers had a deficit in incidence of malignant melanoma (SIR 0.50, 95\% CI 0.35-0.70) and nonmelanoma skin cancer (SIR 0.59, 95\% CI 0.49-0.71). Neither kidney nor bladder cancer showed an increased incidence in the total cohort or in the country-specific subcohorts.

In the analysis by job group, the workers ever employed in asphalt mixing plants or as roofers experienced a lower incidence of stomach and lung cancer than the road pavers did (table 3 ). The latter group was

Table 2. Standardized incidence ratios (SIR) of selected cancers among the bitumen workers by country. $(0=0$ bserved cases, $95 \% \mathrm{CI}$ $=95 \%$ confidence interval)

\begin{tabular}{|c|c|c|c|c|c|c|c|c|c|c|c|c|c|c|c|}
\hline \multirow[t]{2}{*}{ Cancer site ${ }^{\mathrm{a}}$} & \multicolumn{3}{|c|}{ Denmark } & \multicolumn{3}{|c|}{ Finland } & \multicolumn{3}{|c|}{ Norway } & \multicolumn{3}{|c|}{ Sweden } & \multicolumn{3}{|c|}{ Total } \\
\hline & 0 & SIR & $95 \% \mathrm{Cl}$ & 0 & SIR & $95 \% \mathrm{Cl}$ & 0 & SIR & $95 \% \mathrm{Cl}$ & 0 & SIR & $95 \% \mathrm{Cl}$ & 0 & SIR & $95 \% \mathrm{Cl}$ \\
\hline I cancers (140-208) & 850 & 0.96 & & 65 & 0.73 & $0.56-0.93$ & 338 & 0.77 & & 194 & 0.95 & & 1447 & 0.89 & \\
\hline Lip (140) & 16 & 2.08 & $1.19-3.38$ & 0 & 0 & $0-4.17$ & 4 & 1.06 & $0.29-2.70$ & 0 & 0 & $0-2.81$ & 20 & 1.46 & 2.26 \\
\hline Stomach (151) & 37 & 1.49 & $1.05-2.05$ & 1 & 0.21 & $0.01-1.20$ & 28 & 1.24 & $0.82-1$ & 10 & 1.19 & $0.57-2.12$ & 76 & 1.26 & \\
\hline Colorectum (153-154) & 88 & 0.85 & $0.68-1.05$ & 5 & 0.75 & $0.24-1.75$ & 49 & 0.77 & $0.57-1.02$ & 21 & 0.87 & $0.54-1.33$ & 163 & 0.83 & $0.71-0.97$ \\
\hline Lung (162) & 187 & 1.27 & $1.10-1.47$ & 18 & 1.29 & $0.77-2.04$ & 61 & 1.05 & $0.81-1.36$ & 24 & 1.13 & $0.72-1.68$ & 290 & 1.21 & $1.07-1.36$ \\
\hline Melanoma (172) & 11 & 0.43 & $0.22-0.77$ & 1 & 0.24 & $0.01-1.32$ & 11 & 0.42 & $0.20-0.93$ & 11 & 0.94 & $0.47-1.69$ & 34 & 0.50 & $0.35-0.70$ \\
\hline Nonmelanoma skin cancer (173) & 98 & 0.66 & $0.54-0.81$ & 2 & 0.12 & $0.01-0.44$ & 8 & 0.47 & $0.20-0.93$ & 4 & 0.51 & $0.14-1.31$ & 112 & 0.59 & $0.49-0.71$ \\
\hline Bladder (188) & 75 & 0.97 & $0.76-1.22$ & 1 & 0.26 & $0.01-1.43$ & 22 & 0.81 & $0.51-1.23$ & 14 & 0.98 & $0.53-1.64$ & 112 & 0.91 & $0.75-1.10$ \\
\hline Kidney (189) & 28 & 1.12 & $0.74-1.62$ & 2 & 0.69 & $0.06-1.78$ & 9 & 0.59 & $0.27-1.12$ & 5 & 0.55 & $0.18-1.28$ & 44 & 0.82 & $0.60-1.11$ \\
\hline
\end{tabular}

a Code from the 9 th revision of the International Classification of Diseases in parentheses. 
Table 3. Standardized incidence ratios (SIR) of selected cancers by ever employment in specific job groups. ${ }^{\text {a }}(0=0$ observed cases, $95 \%$ $\mathrm{Cl}=95 \%$ confidence interval)

\begin{tabular}{|c|c|c|c|c|c|c|c|c|c|c|c|c|c|c|c|}
\hline \multirow[t]{2}{*}{ Cancer site ${ }^{b}$} & \multicolumn{3}{|c|}{$\begin{array}{l}\text { Road } \\
\text { pavers }\end{array}$} & \multicolumn{3}{|c|}{$\begin{array}{l}\text { Asphalt-mixing } \\
\text { plant work }\end{array}$} & \multicolumn{3}{|c|}{ Roofers } & \multicolumn{3}{|c|}{$\begin{array}{l}\text { Unknown and } \\
\text { mixed jobs }\end{array}$} & \multicolumn{3}{|c|}{$\begin{array}{l}\text { Other bitumen } \\
\text { workers }\end{array}$} \\
\hline & 0 & SIR & $95 \% \mathrm{Cl}$ & 0 & SIR & $95 \% \mathrm{Cl}$ & 0 & SIR & $95 \% \mathrm{Cl}$ & 0 & SIR & $95 \% \mathrm{Cl}$ & 0 & SIR & $95 \% \mathrm{Cl}$ \\
\hline All cancers (140-208) & 842 & 0.90 & $0.84-0.96$ & 74 & 0.67 & $0.53-0.85$ & 71 & 0.97 & $0.75-1.22$ & 10 & 0.43 & $0.20-0.78$ & 496 & 0.95 & $0.87-1.03$ \\
\hline Stomach (151) & 50 & 1.29 & $0.96-1.70$ & 3 & 0.65 & $0.13-1.90$ & 1 & 0.43 & $0.01-2.37$ & 2 & 1.69 & $0.20-6.10$ & 21 & 1.37 & $0.85-2.09$ \\
\hline Lung (162) & 164 & 1.26 & $1.08-1.47$ & 13 & 0.80 & $0.42-1.36$ & 11 & 1.06 & $0.53-1.90$ & 2 & 0.67 & $0.08-2.43$ & 104 & 1.19 & $0.97-1.44$ \\
\hline Nonmelanoma skin cancer (173) & 45 & 0.52 & $0.38-0.70$ & 6 & 0.55 & $0.20-1.21$ & 9 & 0.70 & $0.32-1.33$ & 1 & 1.09 & $0.03-6.05$ & 56 & 0.66 & $0.50-0.86$ \\
\hline Bladder (188) & 62 & 0.94 & $0.72-1.20$ & 9 & 1.16 & $0.53-2.21$ & 5 & 1.05 & $0.34-2.46$ & 0 & 0 & $0-2.52$ & 42 & 0.92 & $0.67-1.25$ \\
\hline
\end{tabular}

a Since workers can be employed in more than one job group, the totals in this table do not correspond to the totals in table 2 .

${ }^{b}$ Code of the 9th revision of the International Classification of Diseases in parentheses.

Table 4. Relative risk (RR) of selected cancers by time since first employment. ( $95 \% \mathrm{Cl}=$ confidence interval, $0=0$ bserved cases)

\begin{tabular}{|c|c|c|c|c|c|c|c|c|c|}
\hline \multirow[t]{3}{*}{ Cancer site } & \multicolumn{8}{|c|}{ Years since first employment } & \multirow{3}{*}{$\begin{array}{l}\text { Test for } \\
\text { trend } \\
\text { (P-value) }\end{array}$} \\
\hline & \multicolumn{2}{|c|}{$1-14^{\text {a }}$} & \multicolumn{3}{|c|}{$15-29$} & \multicolumn{3}{|c|}{$\geq 30$} & \\
\hline & 0 & $\mathrm{RR}^{\mathrm{b}}$ & 0 & $\mathrm{RR}^{\mathrm{b}}$ & $95 \% \mathrm{Cl}$ & 0 & $\mathrm{RR}^{\mathrm{b}}$ & $95 \% \mathrm{Cl}$ & \\
\hline All cancers & 475 & 1.00 & 755 & 0.99 & $0.86-1.14$ & 217 & 1.16 & $0.95-1.41$ & 0.2 \\
\hline Stomach & 32 & 1.00 & 33 & 1.06 & $0.58-1.91$ & 11 & 1.18 & $0.51-2.73$ & 0.7 \\
\hline Lung & 100 & 1.00 & 151 & 0.87 & $0.64-1.18$ & 39 & 1.08 & $0.69-1.68$ & 1.0 \\
\hline Nonmelanoma skin cancer & 41 & 1.00 & 60 & 0.89 & $0.53-1.49$ & 11 & 1.15 & $0.50-2.62$ & 0.9 \\
\hline Bladder & 29 & 1.00 & 61 & 1.16 & $0.66-2.02$ & 22 & 1.85 & $0.90-3.78$ & 0.1 \\
\hline
\end{tabular}

a Reference category.

${ }^{\mathrm{b}}$ Adjusted for age, calendar period, and country.

the only one to show an increased incidence of lung cancer. The results were unremarkable for nonmelanoma skin cancer and bladder cancer.

The overall cancer incidence remained below expectation during the entire follow-up, and the deficit decreased with time since first employment (table 4) (Pvalue of test for trend 0.2 ). No increase in the standardized incidence ratio with increasing time since first employment was suggested for stomach and lung cancers, melanoma or nonmelanoma skin cancer (results not reported in detail). However, the standardized incidence ratios for bladder cancer appeared to increase with longer time since first employment, and they were greater than expected for $\geq 30$ years since first employment (SIR $1.30,95 \%$ CI $0.81-1.96)$. This tendency of the risk of bladder cancer to increase with longer time since first employment was confirmed in a Poisson regression, with a relative risk of 1.85 (95\% CI $0.90-3.78$ ) for $\geq 30$ years since first employment and a P-value of test for trend of 0.1 (table 4).

Smoking status was obtained for 799 men in the Norwegian subcohort, mainly from the 1980s. Of these, 534 (67\%) were reported to be current or former smokers, and 265 (33\%) were reported to be never-smokers. The proportion of ever-smokers in the Norwegian male population aged 16-74 years in 1985-1989 was 69\% (National Council on Tobacco and Health, personal communication).

\section{Discussion}

Our results indicate an increased incidence of lung cancer among Nordic asphalt workers, an excess of pleural cancer based on few cases, and an increased incidence of lip and stomach cancer in Denmark but not in the other countries. There was a suggestion of an increase in the incidence of bladder cancer with longer time since first employment. The incidence of other neoplasms was not increased, either relative to the general population or with increasing time since first employment.

Our results do not indicate an increased risk for any of the investigated low-mortality cancers, with the possible exception of bladder cancer. A small increase in the risk of lung cancer was found, and this increase is in line with previous results based on the same cohorts from Denmark, Norway, and Finland (9,12-15), while the Swedish results indicated no increased risk (8). We also found an increased incidence of lip and stomach cancer in Denmark, but not in the other countries.

Our study had important advantages. It comprised the largest population of asphalt workers ever analyzed for cancer incidence, and it was based on high-quality data for cancer incidence follow-up and on standardized information on employment. Among the limitations of our study were the lack of information on the off-season jobs of the asphalt workers during the time when 
their main employment was with the asphalt industry, the lack of complete occupational histories outside the asphalt industry, and the limited data on tobacco smoking.

The enhanced risk of lung cancer among bitumen workers parallels the findings of the mortality analysis (8). The risk of lung cancer does not appear to increase with time since first employment. Coal-tar exposure may have contributed to the increased lung cancer incidence. In earlier decades, in the Nordic countries, coal tar was added to asphalt to the amount of $0.5 \%$ of the asphalt mass, but this practice was discontinued in 1965-1970. The PAH exposure of asphalt workers has been estimated to have decreased 6-14\% per year between 1970 and 1997 (6). Other possible factors contributing to the risk of lung cancer in this cohort are exposure to asbestos and diesel exhaust (most asphalt machines are powered by diesel engines). Four cases of pleural cancer were observed in the Nordic cohort. However, asbestos use in asphalt work in the Nordic countries has been limited to a few circumstances, and most of the asbestos exposure probably occurred in other jobs held by the workers. The information on smoking in our study was limited to Norway, but it indicates that the smoking habits of asphalt workers may not differ much from those of the general male population of that country. Unfortunately, limitations of the available smoking data preempted more detailed analyses. In conclusion, the increased incidence of lung cancer among Nordic asphalt workers cannot be attributed with certainty to exposure to bitumen fume or to other agents occurring in this industry. More-refined exposure assessment may help address this limitation in future analyses.

We did not find any excess of either bladder or kidney cancer. These results parallel those of the mortality analysis $(8,11)$. However, we did observe a tendency, albeit not statistically significant, for bladder cancer incidence to increase with time since first employment. Bladder cancer was reported to be increased among highway maintenance workers (18) and in a case-control study of bladder cancer in Denmark, in which the effect of exposure to "kerosene and asphalt" was assessed $(19,20)$. An elevated risk of bladder cancer among asphalt workers may reflect their exposure to $\mathrm{PAH}$, since PAH have been implicated as bladder carcinogens (21).

We found a slight increase in the incidence of stomach cancer, which was more pronounced in Denmark, and no trend with time since first employment. The results of the mortality analysis were unremarkable (8, 11). We have no information on the dietary and other lifestyle habits of the workers. An elevated risk of stomach cancer among highway maintenance workers was reported by Maizlish and her colleagues (18). Substantial exposure to "asphalt" was also associated with stomach cancer in a case-control study from Montreal (22).
We found a decreased incidence of malignant melanoma in all four countries; this finding is in contrast to the results of the mortality analysis, in which nonsignificantly increased mortality was detected for Finland and Sweden (11). Since the 5-year survival from malignant melanoma is about $90 \%$ for men (23), incidence data are superior to mortality data when the risk of this disease is being evaluated. This approach is also applicable to the analysis on nonmelanoma skin cancer, for which we found no excess. Maizlish and her coworkers (18) reported doubled mortality from skin cancer (all types, mainly melanoma) among highway maintenance workers in California. However, other groups of outdoor workers, like farmers, in the Nordic countries have a low incidence of skin cancers (24). Gradual tanning may have a protective effect, as a Danish casecontrol study indicated (25).

The increased incidence of lip cancer in Denmark, but not in the other countries, may have been due to chance or to lifestyle factors such as cigar or pipe smoking. It is of interest to note that increased lip cancer incidence has been found for other Nordic outdoor workers (24).

In conclusion, the results of this study confirm the pattern of cancer risk detected in the mortality analysis of the European cohort $(8,11)$. No excess risk was suggested for neoplasms with good survival, for which cancer incidence data are more appropriate than mortality figures, with the possible exception of bladder cancer.

\section{Acknowledgments}

The international component of the study was supported by the European Commission (grant no BMH4CT95-1100) and by European Asphalt Pavement Association, Eurobitume and Concawe. The Finnish component of the study was funded by the Finnish Work Environment Fund. The Norwegian component of the study was funded by the Norwegian Asphalt Entrepreneur Association, the Oslo Road Maintenance Service, the Public Roads Administration, the Working Environment Fund of the Confederation of Norwegian Business and Industry, and the Working Environment Fund of Statoil. The Swedish component of the study was supported by the Swedish Council of Working Life and the Development Fund of the Swedish Construction Industry.

\section{References}

1. Brandt HC, de Groot PC, Molyneux MK, Tindle PE. Sampling and analysis of bitumen fumes. Ann Occup Hyg 1985; 
29:27-80

2. Burstyn I, Kromhout H, Boffetta P. Literature review of levels and determinants of exposure to potential carcinogens and other agents in the road construction industry. AIHA J 2000;61:715-26.

3. International Agency for Research on Cancer (IARC). Coaltars and derived products. In: Polynuclear aromatic compounds, part 4: bitumens, coal-tars and derived products, shale-oils and soots. Lyon: IARC; 1985. p 83-159. IARC monographs on the evaluation of the carcinogenic risk of chemicals to humans, vol 35 .

4. International Agency for Research on Cancer (IARC). Coaltars. In: Overall evaluations of carcinogenicity: an updating of IARC monographs volumes 1 to 42. Lyon: IARC; 1987. p 175-6. IARC monographs on the evaluation of the carcinogenic risk of chemicals to humans, suppl 7.

5. Partanen T, Boffetta P. Cancer risk in asphalt workers and roofers: review and meta-analysis of epidemiologic studies. Am J Ind Med 1994;26:721-40.

6. Burstyn I, Kromhout H, Kauppinen T, Heikkilä P, Boffetta P. Statistical modelling of the determinants of historical exposure to bitumen and polycyclic aromatic hydrocarbons among paving workers. Ann Occup Hyg 2000;44:43-56.

7. Burstyn I, Randem B, Lien JE, Langård S, Kromhout H. Bitumen, polycyclic aromatic hydrocarbons and vehicle exhaust: exposures levels and controls among Norwegian asphalt workers. Ann Occup Hyg 2002;46:79-87.

8. Boffetta P, Burstyn I, Partanen T, Kromhout H, Svane O, Langård S, et al. Cancer mortality among European asphalt workers: an international epidemiological study, I: results of the analysis based on job titles. Am J Ind Med 2003;43:1827.

9. Boffetta P, Burstyn I, Partanen T, Kromhout H, Svane O, Langård $\mathrm{S}$, et al. Cancer mortality among European asphalt workers: an international epidemiological study, II: exposure to bitumen fume and other agents. Am J Ind Med 2003:43:28-39.

10. Burstyn I, Boffetta P, Kauppinen T, Heikkilä P, Svane O, Partanen T, et al. Estimating exposures in the asphalt industry for an international epidemiological cohort study of cancer risk. Am J Ind Med 2003;43:3-17.

11. Boffetta P, Burstyn I, Partanen T, Kromhout H, Svane O, Langård S, et al. IARC epidemiological study of cancer mortality among European asphalt workers. Lyon: International Agency for Research on Cancer (IARC); 2001. IARC internal report, no $01 / 003$.
12. Kauppinen T, Heikkilä P, Partanen T, Virtanen S, Pukkala E, Ylöstalo P, et al. Mortality and cancer incidence of workers in Finnish road paving companies. Am J Ind Med 2003; 43:49-57.

13. Randem BG, Langård S, Dale I, Kongerud J, Martinsen JI, Andersen A. Cancer incidence among male Norwegian asphalt workers. Am J Ind Med 2003;43:88-95.

14. Randem BG, Langård S, Kongerud J, Dale I, Burstyn I, Martinsen JI, et al. Mortality from non-malignant diseases among male Norwegian asphalt workers. Am J Ind Med 2003;43:96-103.

15. Bergdahl IA, Järvholm B. Cancer morbidity in Swedish asphalt workers. Am J Ind Med 2003;43:104-8.

16. Engholm G, Englund A. Morbidity and mortality patterns in Sweden. Occup Med 1995;10:261-8.

17. Mattsson B, Rutqvist LE, Wallgren A. Undernotification of diagnosed cancer cases to the Stockholm Cancer Registry. Int J Epidemiol 1985;14:64-9.

18. Maizlish N, Beaumont J, Singleton J. Mortality among California highway workers. Am J Ind Med 1988;13:363-79.

19. Mommsen S, Aagaard J, Sell A. An epidemiological casecontrol study of bladder cancer in males from a predominantly rural district. Eur J Cancer Clin Oncol 1982;18:1205-10.

20. Mommsen S, Aagaard J. Occupational exposures as risk indicator of male bladder carcinoma in a predominantly rural area. Acta Radiol Oncol 1984;23:147-52.

21. Boffetta P, Jourenkova N, Gustavsson P. Cancer risk from occupational and environmental exposure to polycyclic aromatic hydrocarbons. Cancer Causes Control 1997;8:444-72.

22. Siemiatycki J, Gerin M, Dewar R, Nadon L, Lakhani R, Begin D, et al. Associations between occupational circumstances and cancer. In: Siemiatycki J, editor. Risk factors for cancer in the workplace. Boca Raton (FL): CRC Press; 1991. p 141-295.

23. The Cancer Registry of Norway. Cancer in Norway 1997. Oslo: The Cancer Registry of Norway; 2000.

24. Andersen A, Barlow L, Engeland A, Kjærheim K, Lynge E, Pukkala E. Work-related cancer in the Nordic countries. Scand J Work Environ Health 1999;25 suppl 2:1-116.

25. Osterlind A, Tucker MA, Stone BJ, Jensen OM. The Danish case-control study of cutaneous malignant melanoma, II: importance of UV-light exposure. Int J Cancer 1988;42:31924.

Received for publication: 2 February 2004 